\title{
Embedding Ethnocultural Empathy in a Community- Based Health Intervention Writing Assignment
}

\section{Maranda C. Ward}

The George Washington University (maranda@gwu.edu)

\section{Key Ideas Characterizing the Assignment}

In my 8-week online community-engaged course, I place an emphasis on my students learning about achieving health equity through disease prevention and health promotion. The goal is for students to understand the varied social conditions that influence health in order to advance community, population, and public health in the United States. In doing so, they identify ways to prevent unfair and avoidable health differences across U.S. subpopulations of racial/ethnic minorities, or Black, Indigenous, People of Color (BIPOC). The historically pervasive nature of racialized health disparities can be mitigated by practicing empathy towards racial and ethnic minorities disproportionately affected by poor health outcomes. The knowledge students gain and the skills they practice in this course allow them to better relate to, and care for, the complex and shifting community-level needs of racially diverse patient populations.

U.S. census data indicates that where you live determines how long you live. This means it is not enough to focus health education efforts on what people eat or whether they are physically active. Community-based health promotion programs must consider if communities have access to fresh produce and safe green spaces to walk, run, bike, and play. These social determinants of health are at the core of preventing disease. Research shows that people are more likely to be physically, mentally, emotionally, and socially well when they live in communities designed to keep them healthy. In addition to understanding key public health concepts, students uncover why it is important to involve the target population in the design and implementation of community-based health interventions. Students also gather evidence for how best to engage a community of interest in addressing a health disparity.

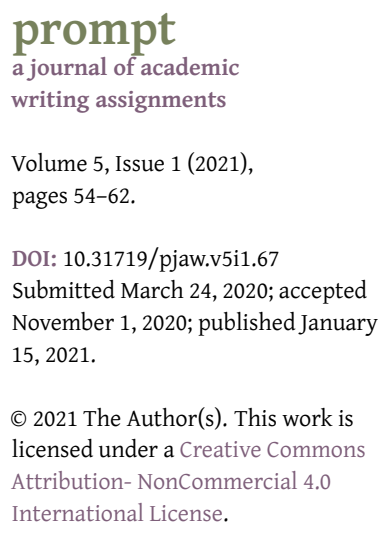

(c) 2021 The Author(s). This work is licensed under a Creative Commons Attribution- NonCommercial 4.0 International License. 
We start by exploring the Healthy People Framework, guidelines created by the U.S. Department of Health and Human Services that articulate the nation's goals for achieving health equity. The factors we discuss-housing, jobs, income, food, transportation, education, neighborhood, social connections, and healthcare-are social structures that cut across multiple sectors. For these reasons, I invite my students to examine why promoting health equity requires an "all hands on deck" approach. Problem-solving solutions to ongoing health disparities call for collaboration, creativity, and empathy. This call is taken up in a paper assignment.

In an 8-page paper, students propose a community-level health intervention. Students select a community and propose a plan using the U.S. Office of Disease Prevention and Health Promotion (n.d.)'s Mobilize-Assess-Plan-Implement-Track (MAP-IT) model. The MAP-IT model is a part of the Healthy People Framework that organizes the learning objectives for the course. Not only must their papers include a proposed community-level intervention to address one local health disparity among a socially disadvantaged population-as outlined in the MAP-IT model-but it must also incorporate the input of a local community-based organization on their proposed intervention. Additionally, their papers include a reflection on the structural inequities faced by BIPOC in their selected community. Students respond to all required discussion board questions as well as instructor and peer feedback throughout the course.

\section{Institutional, Disciplinary, and Course Context}

I teach undergraduates in the School of Medicine and Health Sciences (SMHS) at The George Washington University in Washington, DC. As a subject matter expert, I lead the health equity curriculum efforts for the undergraduate health sciences programs. In fact, I am designing our health equity curriculum thread across a suite of seven undergraduate health sciences courses. A curricular commitment to health equity enhances the capacity and competency of learners. Students learn to confront the structural inequities that fuel health disparities among socially disadvantaged populations.

Promoting empathy addresses racial/ethnic health disparities and works to achieve health equity. In the literature, empathy is a competency achieved and measured in many ways; one of the competencies I am most interested in teaching and assessing is Wang et al.'s (2003) construct of ethnocultural empathy. Ethnocultural empathy is the "ability to perceive the world as the other person does; that is, racial or ethnic perspective taking" (p. 222). Ethnocultural empathy can be measured with a scale of teachable capabilities and individual traits. I designed course activities and assessments for students to practice ethnocultural empathy.

\section{Course Overview}

I revised "HSCI 2110: Disease Prevention and Health Promotion" with an emphasis on health equity. HSCI 2110 is the foundational course in our health equity curriculum core, and empathy is a crucial competency. This course provides the foundation for the remaining undergraduate health science courses, and it integrates health equity objectives, content, and outcomes across undergraduate courses. I teach and serve as the course director for HSCI 2110, an online threecredit course offered every fall semester. All undergraduate health science students enrolled in the Clinical Health Sciences and Clinical Regulatory Affairs B.S. programs must complete HSCI 2110 to graduate. In this asynchronous online course, all students are adult learners, and many are military personnel with a health sciences major. This accelerated course requires 360 hours of contact time in the span of eight weeks.

HSCI 2110 is also a community-engaged course, where students reflect on their civic identities as contributing members of their local (and global) communities. The student-proposed

prompt 5.1 (2021) | Ward, Embedding Ethnocultural Empathy 
project engages in community health education or health promotion-program planning and allows me to assess what pedagogical decisions matter for teaching and assessing ethnocultural empathy.

\section{Precedents and Influences for Creating}

\section{the Assignment}

Health professions education reform is long overdue. The Lancet Independent Global Commission on Education of Health Professionals for the 21st Century (Frenk et al., 2010) identifies how pervasive health disparities necessitate curriculum reform within existing postsecondary education across the fields of allied health, public health, nursing, and medicine. The Commission's report also provides a critique of prevailing learning traditions that focus on knowledge and skill transfer at the expense of building and applying appropriate measurable competencies. For instance, the authors critique the narrow technical focus of curriculum content without broader contextual understanding, the mismatch of existing competencies to patient and population needs, and missed opportunities to build leadership capacity in students. Attention to leadership capacity and other factors can improve health systems. The report commentary serves as a call to act, admonishing educators to move the needle from learning outcomes that are informative to those that are transformative. Only with transformative learning can health professionals apply their competency-based training to address the dynamic needs of an increasingly diverse patient population amidst a shifting and complex health system.

On the heels of the Commission's recommendations, a group of U.S. university researchers designed a qualitative research study to assess the leadership competencies of 32 medical students enrolled in mentored co-curricular activities within their Global Health and Disparities Path of Excellence (Mullan et al., 2014). The capstone project, mentorship program, and connections to professional networks not only aligned with students' career interests, but also sought to develop competencies aimed at eliminating disparities in medically underserved settings. While cultural competency remains ill-operationalized within the study, the researchers did document the use of student reflection on a leadership competency necessary to make healthcare decisions. More pointedly, the study offers several insights for my own scholarship on using reflection to assess empathy as a competency for undergraduate students enrolled in a health equity-based course. Therefore, I designed this reflection-based assignment as a way for students to practice ethnocultural empathy.

\section{Experiences Teaching the Assignment}

I designed the final paper assignment so that students are adequately prepared and supported in their comprehension and application of key health equity-based concepts. The health equitybased content of this course teaches students about historical and structural barriers, and determinants of health that unfairly and adversely affect BIPOC. Course content includes data reports, patient narratives, and research statistics that often highlight the disparate rates of morbidity and mortality among BIPOC. Students receive feedback on their ideas and can edit and adjust their proposal papers accordingly.

\section{Ongoing Support for Submission of Final Paper}

By the time they get to week 3, students post discussion board responses on community-engaged prompts such as, "In what ways can you assess the community?" In response, students initially 
reference local and state data on a specific health disparity. But, with additional questions in the same discussion board, students are encouraged to identify existing resources in the community. I invite my students to consider community assets including the interests, skills, and strengths of the community. Students then name everything from local gatekeepers and civic associations to recreation centers and parks as community resources. This discussion board thread primes students to explore what is meant by asset-based, participatory, and sustainable community partnerships.

When it comes to being participatory, I invite students to consider the role of the community in implementing the intervention (e.g., grassroots versus top-down). To this end, students must identify one non-profit hospital/clinic or community-based organization that can speak to the assets and needs of their community. In addition, students explore how the community gatekeepers can sustain the intervention over time.

I discuss how the language students use is important for framing their communities of interest, identifying unfair health disparities, and proposing an intervention that engages the community for the long haul. As an example, I point out how the term "at-risk" is both stigmatizing and pathologizing. We also discuss how disparities exist in populations but not patients to justify why they are invited to select a community. An essential part of their final project includes community partnerships and planning, and an equity lens is a critical component of their proposed intervention. This is why the discussion board assignments support students' understanding of community gatekeepers, assessing community needs, and employing community engagement strategies. By employing community engagement strategies, students create a vested interest from a range of stakeholders. This makes addressing one selected health outcome sustainable.

By week 4, students translate their ideas into a short paper about how the community will engage in the proposed project. Students prepare a two-three page draft of their final paper organized around each of the five sections of the MAP-IT (Mobilize-Assess-Plan-ImplementTrack) model. I instruct the students to respond to the questions under each of the sub-sections from the U.S. Office of Disease Prevention and Health Promotion's (n.d.) website to help them think of what information needs to go in each section (see the assignment below).

First, they introduce their proposed initiative and the community it engages-citing data from the Healthy People Framework. In this "Mobilize" step, they also consider the principles of health education and health promotion from the course textbook and consider how they intend to involve the community. At this point in the course, the students receive substantial feedback from me on how they demonstrate their understanding of health disparities, social determinants of health, community assessment and engagement, as well as the application of the MAP-IT model to aid in their planning.

In this draft, students must include the name and target population of their community partner from the previous week's discussion board. The paper is staged in this way so that when students submit their final paper, they can contact their organization and describe what they see as the needs and assets of their community. In their final paper, they explain how their proposals are useful in the work of the community-based organization. This draft serves as the basis of their final project.

Teaching the proposal in stages allows students' papers to improve over the course of the semester. For instance, one student wrote about their interest in addressing the growing obesity epidemic in their local community in their week 3 discussion board post. This student translated their understanding of the social determinants of health into their proposed initiative by focusing on the absence of sidewalks as a structural barrier for residents to be physically active. Between weeks 4 and 7, this student was required to share their proposed ideas with 
identified gatekeepers in their targeted community. After talking with two community leaders, the student agreed that building new sidewalks would be ideal, but time and cost intensive. For immediate results, the student redesigned their initiative using the same tactics as a local running club. The student proposed that twenty well-traveled areas of the city be designated as "activity zones" with signage and minor activity equipment. This would include, as an example, posting signs at the entrance of a local grocery store demonstrating how people could earn 600 steps towards their daily 10,000 step goal if they walked from the store entrance to their car located in the back of the parking lot. The student proposed that local college students in the kinesiology department would take the lead in determining the site-specific measurements. Seeking the input of actual community leaders on the feasibility, design, and/or acceptance of the student proposal makes the theoretical concepts come alive.

With the MAP-IT model, I can ensure that students share power and make decisions with the community. As students complete the "Assess" step in this process, they reflect what Shah (2020) describes as a critical community-based epistemology, because they value community expertise and perceive community members as assets to health promotion. In this way, students seek out community investment in their health interventions that may be sustained beyond a classroom assignment.

By week 7, students are sharing and peer-reviewing the executive summaries of their projects on a discussion board. In their final papers, students are asked in what ways they considered or addressed the input of their peers. Returning to the "activity zones" example, this student was able to expand their initiative with peer input to add a social media component and a capacity to track steps in real time. By the end of the semester, this student's project expanded to include a user-friendly app modeled after the widely used www.meetup.com algorithm so that local residents could input their steps from one zone and neighborhood to the next. The student also updated their proposal to include how this local initiative would rely on community programs alongside social media to promote and publicize its efforts and outcomes. They expressed gratitude to their peers on the discussion board for sharing ideas that they previously had not considered, while recognizing that they still had full autonomy to design their proposed project in ways that made sense to their stated aims and community values.

\section{Successful Outcomes}

A total of 78 students have completed this assignment across four classes. Each time, I integrate an IRB-approved 5-point Likert scale pre/posttest instrument of six items to assess self-reported ethnocultural empathy. All enrolled students received an email with a Qualtrics link to the assessment. During the last week of class, I offer the students one extra credit point if they complete the online retrospective posttest. A total of 60 students across four sections of this course in the Fall of 2018 and Fall of 2019 completed it. To evaluate my ability to teach and assess self-reported accounts of empathy, I assessed the results of the pre- and post-tests using Wang et al.'s (2003) Scale of Ethnocultural Empathy. When assessing students' recognition of systemic oppression, in two sections, improvement was significant.

By the end of the course, $86 \%$ of students reported feeling comfortable in discussing controversial topics in text online. The same amount believed that it is possible to learn about sensitive topics by discussing them in text online. These findings are important for a course that relies exclusively on an online format to hold value-laden discussions. On average, $80 \%$ of students enter the course believing that being racially discriminated against impacts one's health, but $90 \%$ leave the course with this understanding. Additionally, $83 \%$ of students across all four sections enter the course believing that health is more than healthcare, but $98 \%$ leave the 
course with an understanding of community factors in health equity. These health equity-based attitudes parallel the students' self-reported increase in understanding the health implications of racial bias and discrimination.

\section{Students' Experiences Completing the Assignment}

Assessing community needs is no easy feat. I assume that a good number of students are accustomed to researching statistics and then interpreting community needs. When asked to reflect on what it is like thinking of and engaging the community when designing an intervention, the vast majority of students mention how it runs counter to how they are accustomed to thinking about health promotion activities. To extend this point, one student explains that it "was an exercise in keeping an open mind and not being too married to an idea before doing much research because chances are... if you talk with people who have done that work before you can perhaps save some time by not repeating mistakes." Students came to value the expertise and lived experience of residents and community anchors alongside data. This is especially important for working with socially disadvantaged populations such as BIPOC. Still, not everyone comes to this realization easily.

Why is everything about race? This is the question I can count on being asked in every HSCI 2110 course. As the course unfolds with lectures that differentiate between health differences and health disparities and rely on scores of data and practitioners' perspectives, students begin to recognize how improving the health of the least socially advantaged groups improves the health of all. One student writes, "I think it is extremely important for healthcare professionals to be aware of their racial biases." Another shares that they "realize the disadvantage that some people have just because of the color of their skin." The reflective writing prompts in the final paper follow discussions of science and medicine justifying discriminatory, substandard, and unethical medical practices for racial minority groups. Students also share the belief that "for us to achieve health equity for vulnerable populations, we must first recognize biases and remove them as a barrier." Across student writing, it is clear that they recognize how being racially discriminated against affects health.

To provide evidence for how achieving healthy equity benefits everyone, I review housing and job laws and explore what access to quality schools and food looks like. Yet, there remain some students who are not sold on the idea that social policy is health policy. In fact, some students describe healthcare as a privilege rather than a right. Across their reflective writing, some students subscribe to the idea that people choose to be poor, referencing their own privileged lives as an exemplar for BIPOC to follow. These types of comments co-exist with their acknowledgement of how racial bias, "affect[s] groups of people who have typically experienced obstacles to their healthcare based on their race," as one student put it. There exists a tendency to compartmentalize these ideas rather than review and critique them as a historical and interrelated system of oppression. Students can recognize that racialized oppression exists, but being aware of oppression does not automatically translate into expressing empathy. This explains the need for perspective taking as another measurable subscale for assessing ethnocultural empathy.

A memorable paper included a fictional elderly Black patient who often relied on the emergency room for services that are offered by primary care providers. In their writing, the student does not denigrate this patient for not establishing a medical home. Instead, they recognized the varied barriers to accessing quality healthcare services. In talking with local faith leaders, this student came up with an idea to engage a group of well-respected off-duty and retired EMS personnel to provide home healthcare to elderly patients who have a hard time getting to and from scheduled appointments. In papers like this one, students readily identify key 
community gatekeepers and even propose carefully designed ideas to address rapport and trust in patient-provider relationships.

Yet, assessing outcomes is challenging and contradictory. The majority of students erroneously conflate structural health outcomes such as increasing access to healthcare or reducing infant mortality rates with what they can feasibly do in a small individual-level intervention (e.g., increasing steps or self-efficacy). This is the type of feedback I provide to students in their drafts that they often do not address in their final paper.

\section{Further Development}

I designed online course activities for adult learners to think about racial oppression as a budding and/or current practitioner. The final paper requires them to describe how the perspectives of $B I P O C$ who face injustice have shaped their proposed community intervention. They are also asked to offer recommendations on how best to mitigate the racial bias that may show up in community-based interventions. In my observation, opportunities to fully consider racially motivated oppression is often thwarted by socially ingrained notions of personal responsibility. For instance, when asked to share their thoughts on the historical disadvantages to achieving health equity for BIPOC, many students credit the course discussions for expanding their understanding of how race-based medicine, bias, stigma, and other structural inequities shape disparate health outcomes for racial and ethnic minorities. However, the meritocracy narrative is pervasive, as students resort to solutions that place the onus on individuals to just "take charge of their health," despite the structural threats to care and human dignity they identify.

Further research is necessary to determine how learner identity shapes the construction and meaningfulness of this assignment. For instance, how students own racial and ethnic identity informs their capacity for ethnocultural empathy is largely unknown. Some students disclose their racial identities in their reflections, while others did not. On the one hand, one could argue that empathizing with BIPOC is a skill only useful for students who do not identify as members of any given racial/ethnic social group. Yet, there is no evidence (within the literature or this course) that this is the case. I could draw from the model minority (Wong \& Halgin, 2006) or involuntary minority (Gibson, 1997) literature to defend why some BIPOC may not necessarily relate to the plight of other BIPOC in their attempt to achieve health equity. In a future version of this assignment, I will include a prompt that explicitly asks about students' social identities and in what ways they believe it affects their ability to take on the perspectives of BIPOC. This prompt is an important addition-and why I have not suggested that one's racial identity predicts their ability to empathize with BIPOC. This would be an erroneous assumption given that one's lived experience is situated at the intersections of varied other identities that often create nuanced and unique social realities. Racialized experiences cannot be essentialized as the sole factor for empathy.

Just as student learners need to reflect on their own identities as they cultivate empathy, instructors are also learners who need to reckon with their own identities. In fact, there is a vast literature on the impact of teacher identity on learning outcomes (Akkerman \& Meijer, 2011; Hockings et al., 2009). Case in point: instructor identities show up in which text examples they select as well as their interpretations of student reflections. The next version of this assignment will include some pre-work for myself and adjuncts who teach sections of this course to remain reflective and transparent about our positionalities. To supplement my written biography, I will add a video introduction talking about my lived experiences and how my upbringing and social identities have shaped how I see inequities, disadvantages, and the role of health professionals.

Finally, I cannot make generalizations based on these data due to the small sample size. At 
the end of the course, students reflect on their previous positions and compare this stance to their current views. Future studies with paired pre- and posttests and assessment questions on the use of reflection will further improve the robustness of evaluation findings. Still, I recognize that there is only so much that can be realistically expected from students in an accelerated online course. Some studies on empathy among medical trainees indicate a decline in empathy that can include self-reported distress from training curriculum (Aparicio et al., 2019; Hojat et al., 2020; Neumann et al., 2011). Between this potential empathy decline and self-recall bias, I cannot rely on this one assignment to translate into more compassionate or patient-centered care. This explains why the course, not merely the assignment, is designed to build capacity for ethnocultural empathy-and why other courses within our undergraduate health equity thread must build on this foundation.

\section{ASSIGNMENT}

In the final paper, you will also develop a plan to address a community health issue using the MAP-IT format that is scoped for your local community (keep the scale small to keep it manageable). Incorporate the feedback you received from your instructor on your MAP-IT paper and the comments from your classmates via the discussion board. Below are elements that must be included in your final paper (along with page minimums):

\section{Mobilize and Assess}

- Define your community- geographically, racially, economically, (including other demographics, as interested) (.5 pg)

- Cite data on the Leading Health Indicators of choice for that community, including its impact (.5 pg)

- Discuss your community needs assessment. You were asked to establish communication with one community based organization of your choice by email and/or phone. What needs and assets did you identify? What did the CBO share on how they can (or do) use that information? How did you use this assessment data to inform the design of your proposed intervention? (2 pgs)

\section{Plan and Implement}

- Describe the health education or promotion plan. (1 pg)

- How is your project designed with health equity in mind? (.5 pg)

- How will you implement the program? What resources will you use? (1 pg)

- Describe how the perspectives of racial/ethnic minorities who face injustices has shaped your proposed community intervention. Additionally, describe your thoughts on being asked to reflect on your ability to consider racial/ethnic perspectives that differ from your own. $(.5 \mathrm{pg})$

\section{Track}

- How will you measure your success? (1 pg)

- How can racial biases show up in a community-based intervention and what plans do you have in place for health professional to address them using your intervention? (.5 pg)

NOTE: Make sure to reference course materials and at least five (5) peer reviewed journal articles. Your final paper is worth 20 points and is due by 11:59pm EST on week 8 . 


\section{Supplementary Material}

For supplementary material accompanying this paper, including a PDF facsimile of the assignment description formatted as the author(s) presented it to students, please visit https: //doi.org/10.31719/pjaw.v5i1.67.

\section{References}

Akkerman, S. F., \& Meijer, P. C. (2011). A dialogical approach to conceptualizing teacher identity. Teaching and Teacher Education, 27(2), 308-319. https://doi.org/10.1016/j.tate.2010.08.013

Aparicio, D. E., Ramos, A. E., Mendoza, J., Utsman-Abarca, R., Calzadilla-Núñez, A., \& Díaz-Narváez, V. P. (2019). Levels of empathy, empathy decline and differences between genders in medical students of Cartagena (Colombia). Educación Médica, 20(Supplement 2), 136-143. https://doi.org/10.1016/ j.edumed.2018.06.004

Frenk, J., Chen, L., Bhutta, Z. A., Cohen, J., Crisp, N., Evans, T., Fineberg, H., Garcia, P., Ke, Y., Kelley, P., Kistnasamy, B., Meleis, A., Naylor, D., Pablos-Mendez, A., Reddy, S., Scrimshaw, S., Sepulveda, J., Serwadda, D., \& Zurayk, H. (2010). Health professionals for a new century: Transforming education to strengthen health systems in an interdependent world. The Lancet, 376(9756), 19231958. https://doi.org/10.1016/s0140-6736(10)61854-5

Gibson, M. A. (1997). Complicating the immigrant/involuntary minority typology. Anthropology \& Education Quarterly, 28(3), 431-454. https://doi.org/10.1525/aeq.1997.28.3.431

Hockings, C., Cooke, S., Yamashita, H., McGinty, S., \& Bowl, M. (2009). 'I'm neither entertaining nor charismatic...' Negotiating university teacher identity within diverse student groups. Teaching in Higher Education, 14(5), 483-494. https://doi.org/10.1080/13562510903186642

Hojat, M., Shannon, S. C., DeSantis, J., Speicher, M. R., Bragan, L., \& Calabrese, L. H. (2020). Does empathy decline in the clinical phase of medical education? A nationwide, multi-institutional, crosssectional study of students at DO-granting medical schools. Academic Medicine, 95(6), 911-918. https://doi.org/10.1097/ACM.0000000000003175

Mullan, P. B., Williams, J., Malani, P. N., Riba, M., Haig, A., Perry, J., Kolars, J. C., Mangrulkar, R., \& Williams, B. (2014). Promoting medical students' reflection on competencies to advance a global health equities curriculum. BMC Medical Education, 14(1), 1-8. https://doi.org/10.1186/1472-6920-14-91

Neumann, M., Edelhäuser, F., Tauschel, D., Fischer, M. R., Wirtz, M., Woopen, C., Haramati, A., \& Scheffer, C. (2011). Empathy decline and its reasons: A systematic review of studies with medical students and residents. Academic Medicine: Journal of the Association of American Medical Colleges, 86(8), 996-1009. https://doi.org/10.1097/ACM.0b013e318221e615

Office of Disease Prevention and Health Promotion. (n.d.). MAP-IT: A guide to using Healthy People 2020 in your community. https://www.healthypeople.gov/2020/tools-and-resources/ProgramPlanning

Shah, R. W. (2020). Rewriting partnerships: Community perspectives on community-based learning. Utah State University Press.

Wang, Y.-W., Davidson, M. M., Yakushko, O. F., Savoy, H. B., Tan, J. A., \& Bleier, J. K. (2003). The scale of ethnocultural empathy: Development, validation, and reliability. Journal of Counseling Psychology, 50(2), 221-234. https://doi.org/10.1037/0022-0167.50.2.221

Wong, F., \& Halgin, R. (2006). The "model minority": Bane or blessing for Asian Americans? Journal of Multicultural Counseling and Development, 34(1), 38-49. https://doi.org/10.1002/j.2161-1912.2006. tb00025.x

prompt 5.1 (2021) | Ward, Embedding Ethnocultural Empathy 